\title{
Statistical analysis of equipment maintenance time in the food industry: a case study to identify sources of impact on performance
}

\author{
El análisis estadístico de los tiempos de mantenimiento a un equipo de la industria \\ alimentaria: un estudio de caso para identificar las fuentes de impacto en el \\ rendimento
}

\author{
Vlamir Faria Barriento ${ }^{1,2} \quad$ Jorge Alberto Achcar ${ }^{1 *}$ \\ Recibido 11 de agosto de 2016, aceptado 19 de marzo de 2018 \\ Received: August 11, 2016 Accepted: March 19, 2018
}

\begin{abstract}
The main goal of this work is related to a study of the maintenance of equipment in a food industry located in São Paulo state, Brazil, using statistical methodology. Several factors can affect the performance of each equipment, for example, type of equipment, fault code, the reason for failure, site installation and technical knowledge of the maintenance workers. From a statistical approach, the maintenance times of the equipments are analyzed under different statistical modeling. The results of this analysis can be of great interest to managers and industry leaders regarding planning on the use of the equipment, detection of the greatest risks in the use of the equipment and to minimize the maintenance stopping times. All these results are of great importance under the production engineering approach in the optimization of its resources.
\end{abstract}

Keywords: Maintenance, autonomy, downtime, stop machines, performance, food industry, statistics analyses.

\section{RESUMEN}

El objetivo principal de este trabajo se relaciona con el estudio de mantenimiento de equipos en una industria alimentaria se encuentra en el estado de Sao Paulo utilizando técnicas estadísticas. Hay varios factores que pueden afectar al rendimiento del equipo, por ejemplo, tipo de equipo, el código de fallo, el motivo del error, la instalación del sitio y el conocimiento técnico de mantenimiento. A partir de un enfoque estadístico de los tiempos de mantenimiento de los equipos son analizados bajo diferentes modelos estadísticos. Los resultados de este análisis pueden ser de gran interés para los gestores y líderes de la industria en términos de planificación sobre el uso de las máquinas, la detección de los mayores riesgos para el uso de las máquinas y reducir al mínimo el tiempo se detiene para los factores de mantenimiento. Todos estos resultados son de gran importancia en el enfoque global de ingeniería de producción para optimizar sus recursos.

Palabras clave: Mantenimiento, autonomia, tiempo de inactividad, máquina parada, rendimento, analises estadísticas, industria alimentaria.

1 Engenharia de Produção. Universidade de Araraquara. Rua Voluntários da Pátria, 1295 - Centro, CEP: 14801-320. AraraquaraSP, Brasil. E-mail: vlamir.barriento@ terra.com.br; achcar@ fmrp.usp.br

2 Engenharia Elétrica. Associação de Ensino de Marília - UNIMAR. Av. Higino Muzi Filho, 1001 - Campus Universitário, Marília - SP, 17525-902. Marília -SP, Brasil. E-mail: vlamir.barriento@terra.com.br

Author Corresponding 


\section{INTRODUCTION}

The industries in all sectors are realizing that it is a critical need to have the proper maintenance on their premises [1-4]. The maintenance process adds value to process regarding profit, quality, time and service [5]. Without a high-quality service, an industry may be at a major disadvantage in the market that increasingly requires low cost and high- quality products to be delivered in short time [2-3, 6-7].

In general, the programming and implementation of maintenance is part of the business planning of any industry, emphasizing the operating revenue, profits and other financial results. Many studies of industrial maintenance consider various indicators to assess the quality of maintenance processes. In practice, these indicators measure efficiency, efficacy, effectiveness, productivity and quality of maintenance actions [8-11].

The maintenance services play an important role in the performance of other sectors within the industry. This role can be summarized in three categories: as a competitive advantage, to support the manufacturing activities and as profit generators [12].

The maintenance management is usually focused on the monitoring of the actions of various industrial programs with quality indicators for the whole process of maintenance, including the phases of planning and implementation. In practice may occur considerable deviations from the original plans. In addition to the uncertainty of the planning phase, due to a lack of failure mechanism of the company's assets, other variables, of random character, may prevent the completion of scheduled maintenance, dictated by unforeseen and flaws in the production system. In particular, the randomness of many failure mechanisms, especially in automated installations, may hinder the prediction of preventative maintenance, affecting the quality of maintenance. Industrial maintenance must follow some criteria of efficiency, efficacy, effectiveness, and production quality. In practice, the use of these indexes may not be enough for a thorough study of maintenance, especially on the discovery of important factors affecting the maintenance time.

Based on [12] services have three main features in their operations which are: the intangibility of services, the need of the customer's presence or an asset of your property and the fact that often the services are produced and consumed simultaneously, that is, there is no stock.

Based on these definitions, service is any act or performance that a party may offer to the other, and that is essentially intangible and does not result in the ownership of anything. Its production may or may not be tied to a physical product, and it cannot be stored.

An asset is defined as a plant, machinery, property, buildings, vehicles and other items that have a distinct value for organizations [13].

Any asset is subject to a deterioration process that progressively prevents us from performing the function for which it was designed. This means that besides the unexpected active break, having a loss of function in an active due to the end of its useful life and in its conditions and time of use could speed up or not wear. Equipment working in hostile environments, or more hours over a period, can wear out much faster. Services in assets is a succinct definition of the maintenance function. The maintenance function usually happens more intensely in some places and equipment in relation to the others. The more critical the process or asset, more necessary the implementation of maintenance and its modern concepts.

The maintenance process (see Figure 1), has as a task, delivering an asset in his condition which was designed to run after receiving the application of hand resource work, parts and processes (tools and knowledge).

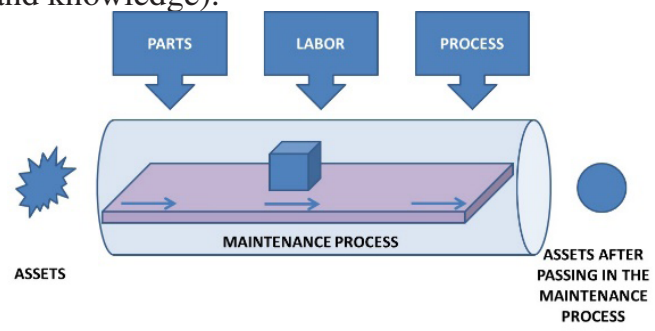

Figure 1. Maintenance Process.

The main goal of any company is to maximize profits, generating wealth for shareholders or owners. Within this context, when there is a break in a piece of equipment impair the range of the production scheduling goals. In 
this way, undertaking the need for the required demand, this problem can affect the production result, and therefore impacting the financial results of the company. To not have this breaking situation and unexpected losses, companies must invest in maintenance.

Within the modern concepts of maintenance, we have several methods and processes that are always looking for better results. The reduction of unscheduled stoppages in machinery and equipment that affect the productivity of the company, either concerning the unavailability of machines, or for loss of quality of its products related to loss of specific equipment functions, is the main goal of the maintenance area. With this goal achieved, we also could achieve another one in parallel, which is the extension of the useful life of the equipment as shown in Figure 2, that is, the maximization in the use of the assets.

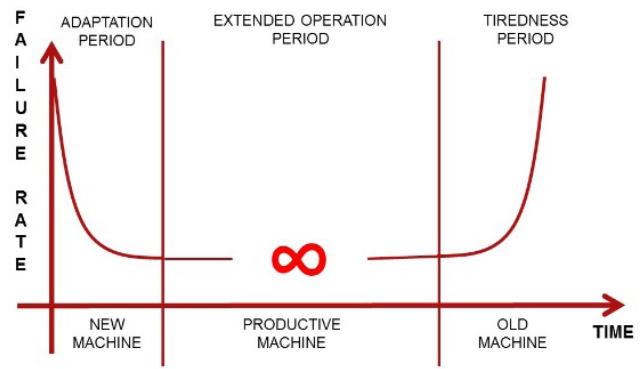

Figure 2. Bathtub curve with prolonged period of operation.

Based on the concepts presented and discussed by some important authors of the area [14-18], we define maintenance as the combination of developed, organized and managed activities to ensure a safe and economically viable operating state of a given system.

\section{MAIN TYPES OF MAINTENANCE}

\section{Corrective maintenance}

Corrective maintenance requires less preparation efforts of maintenance, but at the same time, it is that one that could more negatively impact the results of the area. Corrective maintenance is also known as the most basic concept of maintenance management, having a reactive characteristic, being activated only in time of need. The main disadvantage of this maintenance approach is that the "system" is to say the time that the machine will stop, where corrective maintenance allows the equipment to be "self-manage" concerning the stoppage thereof for maintenance interference.

The main dealings related to corrective maintenance are to record what was previously done with the most possible information. These records are extremely important for a complete follow-up of the history of failures for machines and equipments, which allows us in the identification of the best intervention times with greater assertiveness.

Advantages: Low cost; little need for human resources.

Disadvantages: Increased costs with unplanned stops of equipment; the rising cost of labor, especially if it is necessary to use extra time of maintenance operators; possible damage to secondary equipment for breach of primary equipment; inefficient use of human resources.

\section{Preventive maintenance}

Preventive maintenance is based on a fixed planned to stop maintenance time, either in time frequency or based on the state of the equipment after receiving an inspection. Investing in advance, to be sure you have the resources moments before preventive interventions happen following a previous program could be a great advantage. Under the view of the maintenance team, we could say that this technique has another advantage concerning corrective maintenance, since in this case we have a clear view of what is intended to do at the time of intervention, which permits us to work in a programmed form. Professionals usually like to act in this way, since it is possible to show their enforcement capacity knowledge in a structured way.

Advantages: Effective cost in most cases; flexibility to allow adjustments to the timing of maintenance; increased equipment life; reduction of equipment or process failures; it is estimated a great cost reduction in relation to corrective maintenance.

Disadvantages: catastrophic failures often still occur; intensive use of labor; maintenance execution without need; potential damage in the equipment not requiring maintenance.

\section{Predictive maintenance}

Predictive maintenance is related to find the optimum point to perform preventive maintenance 
on equipment, that is, the point from which the likelihood of equipment failure takes unwanted values. The great difference between the predictive maintenance and preventive maintenance is that before stopping for intervention, maintenance engineering concepts are already applied to diagnose what is happening with the machinery and equipment. In this way, it is possible to program the intervention in an assertive way, acting only where there is the non-compliance, and predicting the time you have for the failure event.

Advantages: Increased availability and service life of the equipment; proactively corrective actions; reduced unscheduled stoppages of equipment and processes; decreasing working costs of parts and labor; better product quality; increased worker and environment safety; increased self-esteem of the workers; estimated reduction of costs regarding to preventive maintenance.

Disadvantages: Increased investment costs for diagnostic equipment; the need for increased staff training.

\section{Reliability centered maintenance (RCM)}

Reliability centered maintenance is a scientific methodology to meet the performance or behavior of the life for products, equipments, plants or processes to ensure that they perform their function without failure over time on a specific condition of use. Reliability is achieved only from the synergy of all directed involved with the activity: operation, maintenance, engineering and others involved indirectly with it. Maintenance focused on reliability consists of a process used to determine what is needed to be done to ensure that any physical item continues to do what its users expect in its present operating context.

This process should answer the following questions:

- What are its functions (what users want it to do)?

- How can it fail?

- What does it fail?

- What happens when it fails?

- How much matter if it fails?

- Is there anything I can do to predict or prevent failure?

- What happens if we cannot predict or prevent failure?
According to [19] "It is not enough to do the right maintenance tasks, you must perform right the right tasks".

\section{STATISTICAL MAINTENANCE DATA ANALYSIS}

In general, any industry or company has large collections of stored maintenance data, such as repair times, days and hours of the occurrence of the maintenance sector where there is the maintenance, day of the week, shift, among many others related to maintenance. By examining the available data, it is possible to discover previously unseen patterns in general not seen by the maintenance workers which could significantly reduce the profit margin of the products [20-21]. In this way arises the need to analyze maintenance data using statistical techniques. The use of statistical techniques allows us to discover important factors on the study of industrial maintenance, for example, sectors of industry where the maintenance time is too high and unacceptable [22]. It is important to note that the use of statistics in the industrial area has been essential since the end of World War II [23]. All companies that want to improve the quality of their products and processes need to concentrate their efforts on the proper use of available data in their records. By examining the available data, it is possible to discover not appropriate patterns unnoticed by the employees that could lead to significant losses in the process and value of their products [20-21].

In particular, the use of statistical techniques in the industrial area has two important points:

- The term "statistical quality control and improvement" should not be restricted to the use of control charts and other statistical methods used in quality control and improvement tools. On the contrary, it should be understood as a deliberate and comprehensive application of simpler tools or more complex statistical methods (including data mining as a popular approach for the analysis of industrial data) with the aim to achieve the quality of the product and process.

- Companies may have decisive significant competitive gains in the market for a consistent application of statistical tools. 
In this way, companies that want to improve their product and process quality need to concentrate their efforts on the proper use of data (internal and external) available in their records [24-25]. All this scenario resulting from the industrial needs to better and better results, is what motivates the use of statistical techniques in the analysis of the maintenance data to detect important factors that lead to the fall of the maintenance quality which implies in high costs and losses for industries.

The study of events of maintenance equipment and the search of possible causes which could significantly increase the maintenance times are of great industrial interest. The analysis of data related to the times to failure or the occurrence of some event of interest such as the maintenance time can lead to better strategies for maintenance of equipment and different types of possible discovered factors that lead to improved performance in maintenance of equipments. Some of these possible factors that could affect the maintenance times are the industry sector, the type of equipment, work shifts, failure causes or maintenance workshops. Maintenance strategies and equipment reliability has been studied extensively by many industrial researchers to optimize industrial performance, as noted in the literature [6-7,26-39].

The main goal of this paper is related to the study of maintenance times of industrial equipment, an area linked to industrial reliability theory. To this purpose, it is analyzed a dataset related to the time of maintenance stoppages due to equipment failure in a large industry in the food sector located in São Paulo State, Brazil. Different statistical methodologies are used to confirm the significant factors in the variability of the data and also to obtain a good forecasting model. As a first statistical analysis of the data, it is considered a usual analysis of variance (ANOVA) model with transformed data on a logarithmic scale (leading to approximate normality of the data) to check possible differences in average times due to various categorical factors. Potentail differences between the different levels of each factor are also verified from confidence intervals for the maintenance mean times. In a second analysis of the data, it is assumed a multiple linear regression model also considering the transformed data to jointly confirm which factors are most important in the variability of the stopping maintenance times and also to be used as a predictive model. The use of different statistical methodologies enriches and confirm the most important factors that control the variability among the maintenance times considered in the study. The discovered factors that can increase these times are important for the industrial managers to take decisions that could mean significant gains for the industry [40-41].

Methodologically this article can be classified as applied [42-44] with a descriptive goal and a quantitative approach.

\section{THE INDUSTRIAL PROBLEM AND A DESCRIPTIVE DATA ANALYSIS}

The food industry in the study is located in the state of São Paulo, Brazil, and operates in the segment of biscuits, toast, chocolate, and snacks. Founded in 1956, it is now established as the second largest manufacturer of biscuits in Brazil, the second most consumed brand and the largest manufacturer in some special products within the segment of biscuits. Like all biscuits industry, its main processes are: receipt of raw materials and inputs, dosing of ingredients, preparation of pasta, molding or rolling, baking ovens, packaging systems and shipping.

Currently the company has eighteen manufacturing lines with equipment from different countries (Italy, France, Germany, England, Brazil, among many others) in 53,000 square meters of built area. It has its plant with a capacity of 170,000 tons per year using modern processes and equipment with high degree of automation. Its product line consists of more than 100 items, including crackers, stuffed, wafers, covered, snacks, cookies and special cookies. Its staff is about 3,000 employees, 1,900 directly linked to the production process, keeping their activities for 24 hours a day seven days a week. In this framework supporting this massive operation, is responsibility of the maintenance area, approximately 159 employees distributed in the following specific sub-areas: safety, environment, building, electrical and electronics, automation, reliability, general maintenance mechanics, mechanics maintenance of packaging machines, warehouse, utilities and planning and control maintenance. All this industrial operation makes the company's products reach, in addition to Brazil, more than 60 countries on all continents. 
In constant search for competitiveness, companies in general, especially for the food company focused in this study, has as a major goal, the elimination of waste, to produce more and more, with fewer resources and less time, and so consequently a production with a lower cost. For this reason, industrial process efficiency indicators have been implemented in order to facilitate the identification of weak points in the production line and thus making possible, the implementation of operational and management strategies to ensure the highest possible productivity. To achieve these goals, the industries seek to keep their processes as automated as possible, in order to extract the best results working around the clock. The advancement of technology has substantially changed the manufacturing processes, both to allow more automation, with clear impact on productivity and consistency and reliability of production, as the challenge of the traditional trade-off between efficiency and flexibility of processes. In largescale production, production systems are organized in order to more easily standardize productive resources (machines, men and materials) and the working methods and controls, contributing to greater system efficiency with consequent cost reduction.

For the data analysis it was considered a dataset of $\mathrm{n}=$ 42,255 observations denoting equipment maintenance times, collected in the industry for four consecutive years for actions related to the production area, corresponding to the period between the years ranging from 2012 to 2015 .

Associated with these observations, we have some factors that may affect the maintenance times of the equipment, as working function, area, service type, the main feature of service and year. In Figure 3, we have the histograms of all original and transformed (logarithmic scale) maintenance times obtained from the MINITAB ${ }^{\circledR}$ software version 16 . From these plots, it is observed better symmetry for the transformed data (approximate normality).

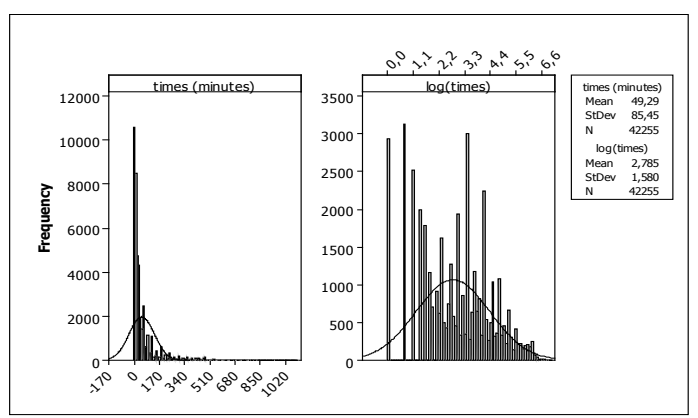

Figure 3. Histograms for original and transformed maintenance times (logarithmic scale)

\section{STATISTICAL ANALYSIS OF THE DATA}

\section{Use of ANOVA (Analysis of Variance) methodology for the maintenance times}

Initially, it was considered an analysis of the variance model with one classification considering the qualitative variables, function, shift, area, type of service, the main feature of the service, the service workshop and year to the transformed data (logarithms of maintenance stop times) using the MINITAB ${ }^{\circledR}$ software version 1.6.

The Analysis of Variance (ANOVA) methodology is a statistical approach to test whether a particular factor has a significant effect on the dependent variable Y. Assuming $\mu_{\mathrm{j}}$ denoting the true mean value of the dependent variable classified in different levels of a factor means that for the level $\mathrm{j}$, the ANOVA technique tests the hypothesis that there are no differences between the means $\mu_{\mathrm{j}}$, assuming no differences between the variability of observations in each group (constant variance). For more details on ANOVA, it is recommended to read [45].

The levels of each factor considered in the ANOVA are given by:

- Function: (1) Maintenance assistant mechanical packaging machines; (2) Maintenance technical mechanics packaging machines; (5) General mechanical maintenance assistant; (6) General mechanical maintenance technicians; (7) Maintenance technicians in electronics; (9) Maintenance assistant in electronics; (13) Others.

- Shift work: (1) First shift (6:00 a.m. to 14:45 p.m.); (2) Second shift (14:45 p.m. to 22:50 p.m.); (3) Third shift (22:50 p.m. to 6:00 a.m.); (4) Fourth shift (10:00 a.m. to 19:00) p.m.; (5) Administrative (8:00 a.m. to 18:00 p.m.).

- Area: (1) Production line 1; (2) Production line 2; (3) Production line 3; (4) Production line 4; (5) Production line 5; (6) Production line 6; (7) Production line 7; (8) Production line 8; (9) Production line 9; (10) Production line 10; (11) Production line 11; (12) Production line 12; (13) Production line 13; (14) Production line 14; (15) Production line 15; (16) Production line 16; (17) Production line 17; (23) Course reserve; (25) Lighting; (26) External ingredients warehouse; (27) Cooling tower; (28) Water treatment; (29) Shipping; (30) Compressed air center; (31) Central 
steam; (32) Gas center; (33) Central generator; (34) Pump's house; (35) Tanks area; (36) Secondary booth; (37) Warehouse; (38) Central packaging; (39) Manufacturing 1; (40) Manufacturing 2; (41) No breaks room; (43) Fat plasticizer; (44) Office; (45) Workshops; (47) Common industrial areas.

- Kind of service: (1) Corrective Maintenance; (2) Scheduled Services (Preventive and Corrective Program); (3) Inspections; (4) Lubrication.

- Main feature of the service: (1) Set; (2) Monitoring Operation; (3) Align; (4) Adapt; (5) To assess; (6) Power Supplies Lock (LOTO); (7) Auxiliary; (8) Inspections; (9) Course Reserve; (10) Repair; (11) Improvements; (12) Grease; (13) Course Reserve; (14) Eliminate leakage; (15) Rearm; (16) Replace; (17) Replace; (18) Remove; (19) Review; (20) Cleaning / Organize; (21) Set Up; (22) Unlock; (23) Identify; (24) Fix; (25) Landing Electrically; (26) Install; (27) Inverter; (28) Improvement; (29) Test.

- Workshop service: (1) Electronics; (2) Packaging Machinery Mechanics; (3) General Mechanical.

- Year: 2012, 2013, 2014 and 2015.

In Table 1, we have the results of this statistical analysis. The needed assumptions to use an ANOVA model (normality of errors and constant variance) were verified from standard residual plots. From the results in Table 1, it is observed that all factors lead to significant differences between the maintenance time (logarithmic scale) as the p-value is less than 0.001 (significant at a significance level equals to 0.1 $\%)$. It is important to note that the sample size is too large, leading to rejection of equal means in all cases.

Table 1. Analysis of variance for the logarithms of maintenance times

\begin{tabular}{|lrrrrr|}
\hline Source & DF & SS & MS & F & P \\
\hline Function & & & & & \\
\hline Factor & 6 & 11738.2 & 1956.4 & 881.75 & $<0.001$ \\
\hline Error & 42248 & 93736.3 & 2.2 & & \\
\hline Total & 42254 & 105474.5 & & & \\
\hline Shift of service & & & & \\
\hline Factor & 4 & 8189.7 & 2047.4 & 889.18 & $<0.001$ \\
\hline Error 42250 & 97284.8 & 2.3 & & \\
\hline Total 42254 & 105474.5 & & & \\
\hline Area of service & & & \\
\hline
\end{tabular}

\begin{tabular}{|c|c|c|c|c|c|}
\hline Factor & 38 & 9321.5 & 245.3 & $\begin{array}{ll}3 & 107.70\end{array}$ & $<0.001$ \\
\hline Error & 42216 & 96153.0 & 2.3 & & \\
\hline Total & 42254 & 105474.5 & & & \\
\hline \multicolumn{6}{|c|}{ Kind of service } \\
\hline Factor & 3 & 51765.5 & 17255.2 & 13574.02 & $<0.001$ \\
\hline Error & 42251 & 53709.0 & 1.3 & & \\
\hline Total & 42254 & 105474.5 & & & \\
\hline \multicolumn{6}{|c|}{ Main feature service } \\
\hline Factor & 26 & 56465.9 & 2171.8 & 1871.29 & $<0.001$ \\
\hline Error & 42228 & 49008.6 & 1.2 & & \\
\hline Total & 42254 & 105474.5 & & & \\
\hline \multicolumn{6}{|c|}{ Service workshop } \\
\hline Fator & 2 & 9971.0 & 4985.5 & 2214.05 & $<0.001$ \\
\hline Error & 42068 & 94726.8 & 2.3 & & \\
\hline Total & 42070 & 104697.8 & & & \\
\hline \multicolumn{6}{|l|}{ Year } \\
\hline Factor & 3 & 1072.0 & 357.3 & 144.61 & $<0.001$ \\
\hline Error & 42251 & 104402.5 & 2.5 & & \\
\hline Total & 42254 & 105474.5 & & & \\
\hline
\end{tabular}

(DF: degrees of freedom; SS: sum of squares; MS: mean squares; F Snedecor distribution; P: p-value)

\section{Confidence intervals for the means}

A second step in the data analysis, as for all the factors we rejected the equality of means, it is constructed confidence intervals for the mean of each level of the considered factors. Since the sample sizes are fairly large, the central limit theorem shows that the sample means is approximately normal. We use this fact to present the $95 \%$ confidence intervals for the means to be considered as multiple comparisons. Overlapping confidence intervals indicate statistical equality of means. Not overlapping confidence intervals indicate differences between the means. In this way, we present the plots of the $95 \%$ confidence intervals for the means in different levels for each factor.

\section{Function}

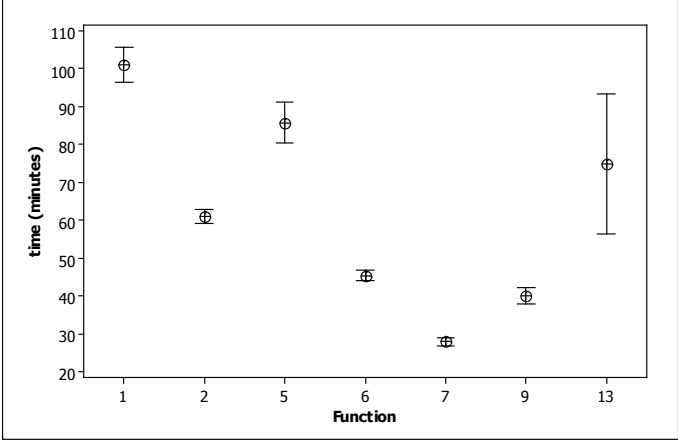

Figure 4. 95\% Confidence Intervals for the average maintenance time for function. 
From the plots in Figure 4, we observe that the levels (6)-General mechanical maintenance technicians; (7)-Maintenance technicians in electronics and (9)-Maintenance assistant in electronics have smaller mean maintenance times when compared to the other levels. Level (1)- Maintenance assistant mechanical packaging machines have larger mean maintenance time.

\section{Shift work}

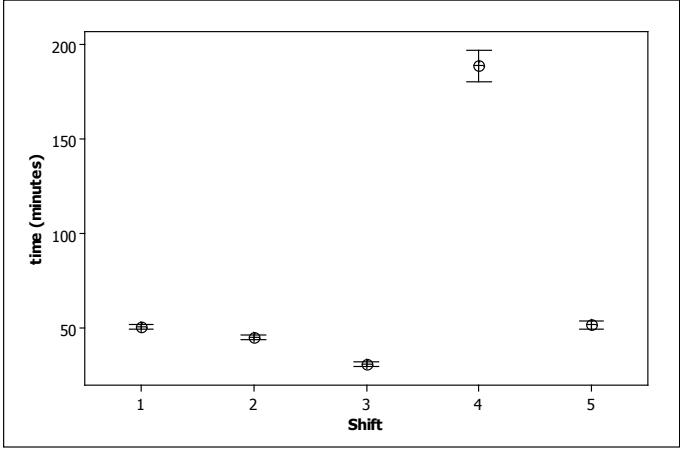

Figure 5. 95\% Confidence Intervals for the average maintenance time for a work shift.

From the plots in Figure 5, we observe that the level (4)- Fourth shift (10:00 a.m. to 7:00 p.m.) has larger mean maintenance time when compared to the other work shifts.

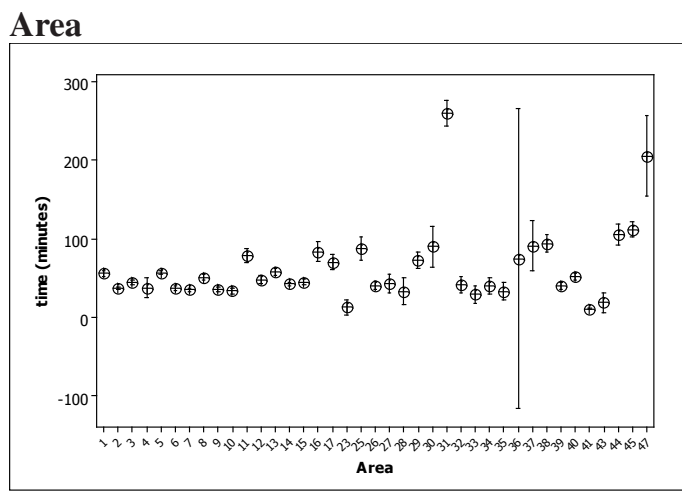

Figure $6.95 \%$ Confidence Intervals for the average maintenance time for the area.

From the plots in Figure 6, we observe that the levels (31)-Central steam and (47)-Common industrial areas have larger mean maintenance time when compared to the other areas. For all the other areas the mean maintenance times are similar.

\section{Kind of service}

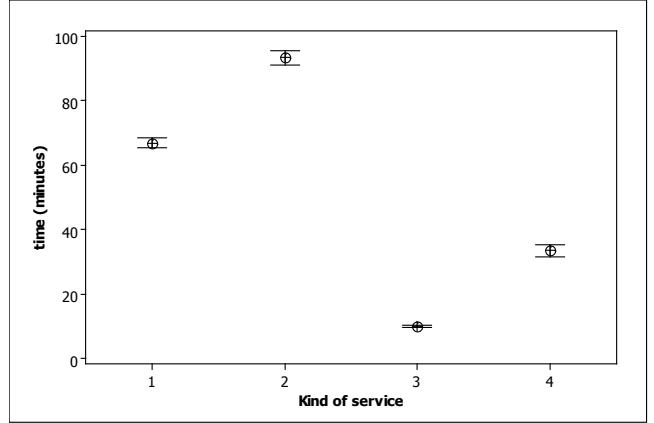

Figure 7. 95\% Confidence Intervals for the average maintenance time for kind of service.

From the plots in Figure 7, we observe that the levels (1)-Corrective maintenance and (2)-Scheduled services (preventive and corrective program) have larger mean maintenance time when compared to the other areas.

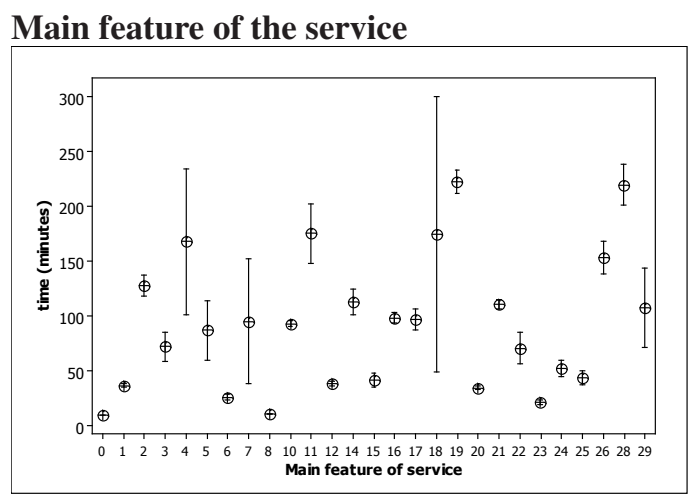

Figure 8. 95\% Confidence Intervals for the average maintenance time for the main feature of service.

From the plots in Figure 8, we observe that for each particularity of service we have different mean maintenance time.

\section{Workshop service}

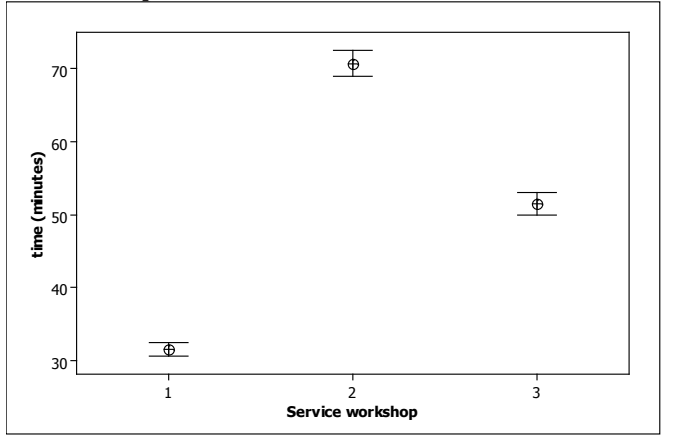

Figure 9. 95\% Confidence Intervals for the average maintenance time for service workshop. 
From the plots in Figure 9, we observe that the service workshop (2)-Packaging machinery mechanics has larger mean maintenance time; in the same way the service workshop (1) Electronics has smaller mean maintenance time.

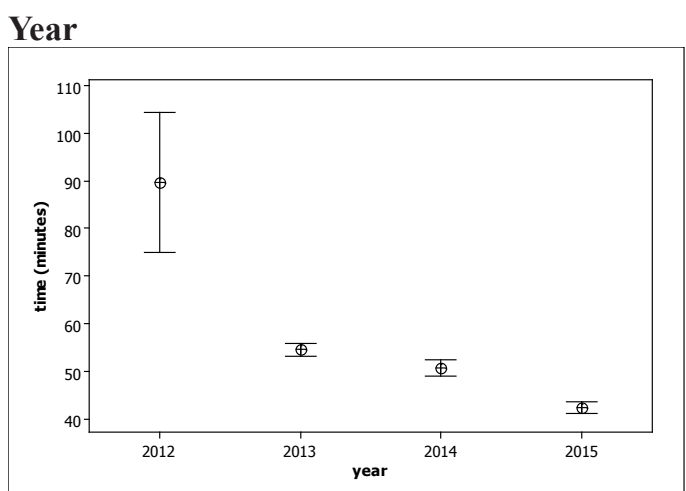

Figure $10.95 \%$ Confidence Intervals for the average maintenance time for a year.

From the plots in Figure 10, we observe that here is a decreasing in the mean maintenance times for each year; in the year 2012, there was a more sifnificant mean maintenance time when compared to the other years.

\section{Use of a multiple linear regression model}

Analyzing the factors separately, it was found from ANOVA techniques or confidence intervals for the averages the important factors that influence the maintenance times. The next step was to analyze the effect of all these factors together, looking for the relevant factors and also to set a model for prediction. In the statistical analysis, when the main objective is to verify the combined effect of covariates on the response $\mathrm{Y}$, usually it is employed multiple linear regression techniques [45-47].

In this way, although most of the covariates are ordinal categorical variables, we assumed a multiple linear regression model that can be useful for predictions, considering the covariates (independent variables) function $\left(\mathrm{x}_{1}\right)$, shift $\left(\mathrm{x}_{2}\right)$, area $\left(\mathrm{x}_{3}\right)$, kind of service $\left(\mathrm{x}_{4}\right)$, the main feature of the service $\left(\mathrm{x}_{5}\right)$, service workshop $\left(\mathrm{x}_{6}\right)$, year $\left(\mathrm{x}_{7}\right)$ and the transformed response given by $\log$ (time maintenance) to meet some necessary assumptions for the use of regression models, given by:

$$
\begin{aligned}
& y_{i}=\beta_{0}+\beta_{1} x_{1 i}+\beta_{2} x_{2 i}+\beta_{3} x_{3 i}+\beta_{4} x_{4 i}+ \\
& \beta_{5} x_{5 i}+\beta_{6} x_{6 i}+\beta_{7} x_{7 i}+\varepsilon_{i}
\end{aligned}
$$

where the errors $\epsilon_{\mathrm{i}}$ are assumed to be independent random variables with normal distribution with mean equals to zero and unknown variance equals to $\sigma^{2}$.

The main goals of using a multiple linear regression model given by equation (1) are:

- To find the joint effects of all factors in the mean of the maintenance times;

- To identify which factors have a significant effect on response maintenance times);

- To find a predictive model.

The multiple regression model fitted by least square estimation (LSE) using the statistical MINITAB ${ }^{\circledR}$ software, version 16, is given by:

$\log ($ time $)=28.0-0.109$ (Function $)+0.117$ $($ Shift $)+0.0166$ (Area) $-0.836($ Kind of service $)+$ 0.0835 (Main feature of service) +0.0733 (Service workshop) - 0.0120(year).

From the obtained results from the MINITAB ${ }^{\circledR}$ software, version 16, given in Table 2, it is observed that all factors except the factor year ( $\mathrm{p}$-value $=0.089$ ) are significant (p-value $<0.001$ ) affecting the maintenance response times. This confirms the results previously obtained by the other statistical analyzes. As the model captures the combined effect of all covariates in response (maintenance service time), possibly the covariate year has some dependence on any of the other covariates, which led to non-significance of the years in the response (maintenance service time). The fitted model (2) could be very useful to make prediction. The residual normality assumption was verified from standard residuals plots (Figure 11). Also are observed from these plots, approximately constant variance for the error.

Table 2. Linear Regression to the logarithms of the maintenance times.

\begin{tabular}{|lcccl|}
\hline Preditor & Coef & SE Coeff & T & P \\
\hline Constant & 27,96 & 14,20 & 1,97 & 0,049 \\
\hline Function & $-0,108937$ & 0,002945 & $-36,99$ & $<0,001$ \\
\hline Shift & 0,116590 & 0,004803 & 24,27 & $<0,001$ \\
\hline Area & 0,0166432 & 0,0005263 & 31,62 & $<0,001$ \\
\hline Kind serv & $-0,836468$ & 0,007433 & $-112,54$ & $<0,001$ \\
\hline Main feat serv & 0,083527 & 0,001008 & 82,83 & $<0,001$ \\
\hline Workshop & 0,073251 & 0,007675 & 9,54 & $<0,001$ \\
\hline year & $-0,012013$ & 0,007052 & $-1,70$ & 0,089 \\
\hline
\end{tabular}

(SE: standard error; T: Student T distribution; P: p-value) 


\section{Use of a log-normal regression model}

As another statistical analysis, we could use reliability models for maintenance times with the data in the original scale. The analysis of survival times is related to statistical modeling of components or systems, where positive observations give the variable of interest. In this direction, different probability distributions could be used in the data analysis.
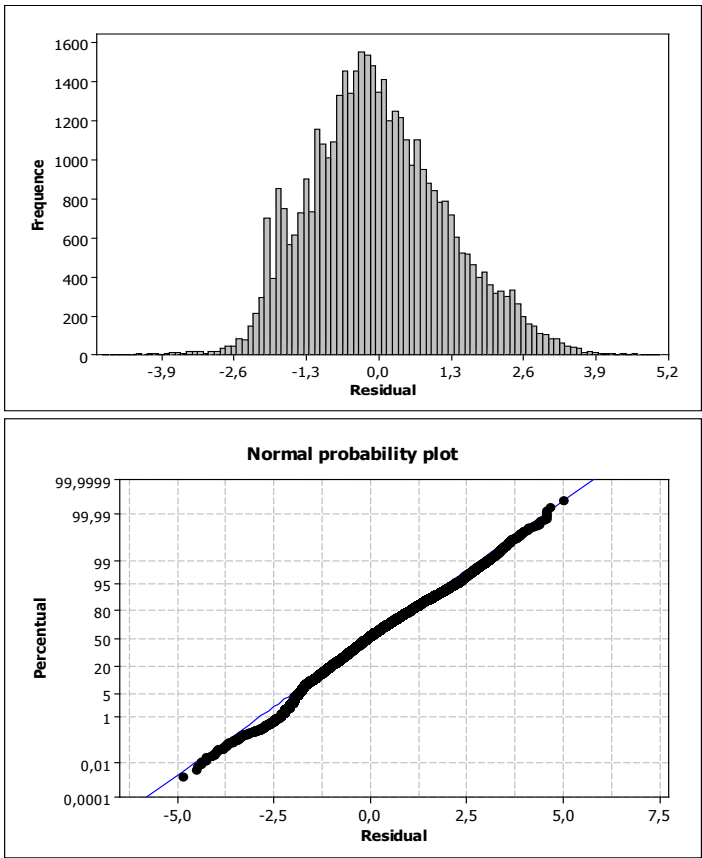

Figure 11. Residual plots (linear regression model)

A trendy model used to analyze reliability data is given by the Weibull distribution [48]. Other possible distributions also could be used: the exponential distribution (a special case of the Weibull distribution), the log-normal distribution, the gamma distribution or generalized gamma distributions [49,50]. These models lead to different failure rates defined as instantaneous failure rate given by $\mathrm{h}(\mathrm{t})=\mathrm{f}(\mathrm{t}) / \mathrm{R}(\mathrm{t})$ where $f(t)$ is the probability density function and $\mathrm{R}(\mathrm{t})=\mathrm{P}(\mathrm{T}>\mathrm{T})$ is the reliability function for a fixed value $\mathrm{t}$ and $\mathrm{P}$ denotes the probability. Different probability distributions lead to different failure rates forms. As regarded in the previous statistical analysis of the maintenance dataset, the normal distribution was suitable for the analysis of the maintenance data considering the transformed data to a logarithmic scale (residual plots given in Figure 11). In this way, the probability distribution for the maintenance times in the original scale is a log-normal distribution with probability density function given by,

$$
\mathrm{f}\left(\mathrm{t}_{\mathrm{i}}\right)=\left[\mathrm{t}_{\mathrm{i}} \sigma\right]^{-1} \exp \left\{-\left[\log \left(\mathrm{t}_{\mathrm{i}}\right)-\mu\right]^{2} / 2 \sigma^{2}\right\}
$$

In the presence of covariates in (3), we assume the regression model for maintenance dataset, given by,

$$
\begin{aligned}
& \mu_{i}=\beta_{0}+\beta_{1} x_{1 i}+\beta_{2} x_{2 i}+\beta_{3} x_{3 i}+\beta_{4} x_{4 i}+ \\
& \beta_{5} x_{5 i}+\beta_{6} x_{6 i}+\beta_{7} x_{7 i}
\end{aligned}
$$

Using the MINITAB ${ }^{\circledR}$ software, version 16 , we obtained the maximum likelihood estimators for the regression parameters in (4) which the same LSE estimates given in Table 2. That is, we get the same inferences.

\section{CONCLUDING REMARKS}

The statistical analysis of the data obtained for the food sector industry may be of great interest in identifying the causes of the great variability for the maintenance times of different equipment used in the industry. The use of different statistical modeling can lead to significant advantages in the inferences and predictions of interest. These gains were observed in the case study using ANOVA techniques (ANOVA) and multiple comparisons techniques based on confidence intervals for the means of each factor level. For the prediction of maintenance times, it has been fitted a multiple linear regression model. With these different models, it was possible to detect the factors that most affect the variability of the data. It is important to note that the statistical approach undertaken in this paper can bring benefits to many other productive systems. With the use of the statistical approach to the selected dataset, we can summarize the following conclusions related to each factor affecting service maintenance times:

\section{Function}

In the electronics maintenance area, we observe lower mean times for the maintenance since the majority of repairs are of a quick solution, even when it is needed longer diagnostic situations, what happens in a few repair cases. In some conditions, such as adjustments and resets of systems, the repairs could be made without needing to stop the equipment for a long time, a fact evidenced here with the data analysis. For the mechanical and 
electronics auxiliary functions it is observed similar mean maintenance times due to the complexity of the repair function in both cases for the diagnosis and resolution of problems. We also note that for the auxiliary mechanical maintenance electricians and building maintenance, there are higher mean times due to lower technical knowledge of these workers to machines related directly to production.

\section{Shift}

An important finding from this study related to maintenance times for different work shifts was to find the greater maintenance mean time in the fourth work shift, since the majority of the activities of this team is correlated with set-ups, improvements and adaptations of machinery and equipment, where it is known that such activities customarily take longer times. In the case of the third work shift, it is observed a much lower mean maintenance time since in this turn there is less interference in production by changes in programming and testing.

\section{Area}

In this case, it is observed that the support areas have less stopping times due to preventive interventions and has a significant impact in all other productive areas. Another important point which should be emphasized is that in some intervention conditions, it is necessary to wait a few moments until the equipment stays in a safe condition of intervention (cooling for example). Even with a special preparation for the intervention, such as providing tools and different resources (aerial platforms, scaffolding devices for handling and lifting, among many others) making maintenance events to be long, which could occur in some special cases.

\section{Kind of service}

It is important to point out that at this time, the studied industry has been scheduling quickly programmed inspections showing that a maintenance plan is being run satisfactorily.

\section{Main service features}

We observe from this study that the most extensive maintenance times are directly related with the maintenance area (adapting, making, removing, installing and improvement), which always require a careful preparation involving the activity in most cases with parts, tools and even a service provider to assist in the event.
As a final concluding remark, it is important to point out that all statistical techniques used in the data analysis led to similar results, although the use of a multiple regression allows one to find predictions based on the joint effect of all factors on the response of interest (time maintenance).

\section{REFERENCES}

[1] J. Luxhoj and U. Thorsteinsson. "Trends and perspectives in industrial maintenance management". Journal of Manufacturing Systems. Vol.16 Issue 6, pp. 437- 453. 1997. ISSN: 0278-6125.

[2] T.D. Stephen. "Positioning maintenance as a competitive advantage". Plant Engineering. Vol. 54 Issue 5, pp. 66-69. 2000. ISBN 978-953-51-3607-1.

[3] C. Cholasuke, R. Bhardwa and J. Anthony "The status of maintenance management in UK manufacturing organizations: results from a pilot survey". Journal of Quality in Maintenance Engineering. Vol. 10 Issue 1, pp. 5 - 15. 2004. ISSN: 1355-2511.

[4] P. Meulen, M. Petraitis and P. Pannese. "Design for maintenance. In: IEEE/SEMI Advanced Semiconductor Manufacturing Conference. pp. 278-281. 2008. DOI: 10.1109/ASMC.2008.4529053.

[5] G. Zhu, L. Gelders and L. Pintelom. "Object/objective oriented maintenance management". Journal of Quality in Maintenance Engineering. Vol. 8 Issue 4, pp. 306- 318. 2002. ISSN: 1355-2511.

[6] L. Swanson "Linking maintenance strategies to performance". International Journal of Production Economics. Vol. 70 Issue 3, pp. 237 - 244. 2001. ISSN: 0925-5273.

[7] L. Swanson. "An information-processing model of maintenance management". International Journal of Production Economics. Vol. 83 Issue 1, pp. 45 - 64. 2003. ISSN: 0925-5273. [8] M.W.Anhesine. "Uma abordagem sistêmica para diagnósticos em manutenção industrial”, EESCUSP, São Carlos, 204 p (Tese de doutorado). 1999.

[9] R.C. Clifton. "Principles of planned maintenance", Edward Arnold Publishers: London. 1974. ISBN: 0713133171.

[10] G. Cokins. "Activity-base cost management: making it work". Irwin Professional Publishing: Chicago. 1996. ISBN: 100786307404. 
[11] B. Gold. "Foundations of strategic planning for productivity improvement". Interfaces. Claremond Graduate School. Vol.15 Issue 3, pp. 15-30. 1985. ISSN: 1526-551X (on line)

[12] I.G.N. Gianese y H.L. Correa. "Administração Estratégica de Serviços", $1^{\text {a }}$ Ed, São Paulo. Atlas, 1994. ISBN 85-224-1152-2

[13] N. Pizzati, D. Mortelari y K.O. Siqueira. RCM na quarta geração da manutenção de ativos. São Paulo: RG Editores, $1^{\mathrm{a}}$ edição. 2011. ISBN: 9788579520327.

[14] L. Tavares. "Excelência na Manutenção", 2." ed. Bahia: Casa da Qualidade, 1996. ISBN 85-85651-03-02.

[15] A. Kardec y H. Ribeiro. "Manutenção: Gestão Estratégica e Manutenção Autônoma". 1. ${ }^{\mathrm{a}}$ ed. Rio de Janeiro: Qualitymark, 2002. ISBN 978-85-7303-806-4.

[16] G. Branco Filho. "A Organização, o Planejamento e o Controle da Manutenção", 1. ${ }^{a}$ ed. Rio de Janeiro: Ciência Moderna. 2008. ISBN: 978-85-7393-680-3.

[17] G. Branco Filho. "Indicadores e Índices de Manutenção", 1. a ed. Rio de Janeiro: Ciência Moderna, 2006. ISBN: 85-7393-491-3.

[18] L.A. Verri. "Sucesso em Paradas de Manutenção", 1. a ed. Rio de Janeiro: Qualitymark, 2008. ISBN: 978-85-7303-813-2.

[19] J. Moubray. "Reliability-Centered Maintenance". Industrial Press. New York, NY, 1997. ISBN: 0-8311-3146-2.

[20] M.R. Beauregard, R.J. Mikulak and B.A. Olson. "A Practical Guide to Statistical Quality Improvement. Opening up the Statistical Toolbox". New York: Van Nostrand Reinhold. 1992. ISBN 9789401179959.

[21] G.E.P. Box and S. Bisgaard. "The Scientific Context of Quality Improvement. A Look at the Use of Scientific Method in Quality Improvement. Quality Progress". pp. 54-61. 1987. ISSN 0033-524X

[22] C. Hope and A. Muhlemann. "Service Operations Management. Strategy, Design and Delivery". London: Prentice Hall. 1997. ISBN-13: 978-0131499157

[23] B.L. Joiner. "Fourth Generation Management. The New Business Consciousness. How the Evolution of Management and the Revolution in Quality are converging, and what it means for Business and the
Nation". New York: McGraw-Hill. 1994. ISBN-13: 978-0071735865

[24] J.M. Juran. "How to think about Quality". In J.M. Juran, A.B. Godfrey, R.E. Hoogstoel, and E.G., Schilling (Eds.): Quality-Control Handbook. New York: McGraw-Hill.1999. ISBN 0-07-034003-X

[25] J.S. Kim and M.D. Larsen. "Integration of Statistical Techniques into Quality Improvement Systems". In Proceedings of the 41st Congress of the European Organization for Quality. 2, 277-284. 1997.

[26] M.T. Almeida. "Manutenção Preditiva: Confiabilidade e Qualidade". Itajubá: Escola Federal de Engenharia, 2007 Disponível em www.mtaev.com.br/download/mnt1.pdf, acessado em 28/07/2007.

[27] A. Kardec and J. Nascif. "Manutenção: Função Estratégica". 2. ${ }^{a}$ ed. Rio de Janeiro: Qualitymark. 2001. ISBN: 9788541400404

[28] B.S. Dhillon. "Engineering Maintainability". Houston: Gulf Publishing Company. 1999. ISBN: 9780884152576.

[29] J. Moubray. "Reliability - Centered Maintenance". Industrial Press. New York, NY, 1997. ISBN 0-8311-3146-2

[30] F.Zhang andA. K. S. Jardine. "Optimal maintenance models with minimal repair, periodic overhaul and complete renewal". IIE Transactions, Vol. 30, pp. 1109-1119. 1998. ISSN 0740-817X

[31] A.H. Christer, W. Wang, J. Sharp and R.D. Baker. "A case study of modelling preventative maintenance of a production plant using subjective data", Journal of the Operational Research Society. Vol. 49, pp. 210-219. 1998. ISSN: 0160-5682

[32] T. Nakagawa. "Maintenance Theory of Reliability”. Springer, London. pp. 201-229. 2005. ISSN: 1614-7839

[33] R. Billiton and A. Ron 1983. Reliability Evaluation of Engineering Systems: Concepts and Techniques. New York: Plenum Press, 1983. ISBN 100306412969

[34] B.S. Blanchard and W.J. Fabrycky. "Systems Engineering and Analysis", 3rd ed., Upper Saddle River, NJ, Prentice-Hall. 1998. ISBN-13: 978-0132217354.

[35] A. Kelly. "Maintenance planning and control", Butterworths. London, 1984. ISBN 13: 9780408013758. 
[36] J. Vatn. "Maintenance optimization from a decision theoretical point of view". Reliability Engineering and System Safety. Vol. 58, pp. 119-126. 1997. ISSN: 0951-8320.

[37] M. Faccio, A. Persona, F. Sgarbossa and G. Zanin. ZANIN. "Industrial maintenance policy development: A quantitative framework". International Journal of Production Economics Vol. 147, pp. 85 - 93. 2014. ISSN: 0925-5273

[38] H.Pham and H. Wang. "Imperfect maintenance". European Journal of Operational Research 94. 425 - 438. 1996. ISSN: 0377-2217

[39] J. M. Hazaras, C.L.E. Swartz and T. Marlin. "Flexible maintenance within a continuos-time state-task network framework". Computers and Chemical Engineering. Vol. 46, pp. 167 -177. 2012. ISSN: 0098-1354

[40] R.V. Brown, A.S. Kahr and C. Peterson. "Decision Analysis for the Manager". New York, Holt, Reinhardt \& Winston. 1974. ISBN-13 9780030861185

[41] B. Al-Najjar. "Total quality maintenance: an approach for continuous reduction in costs of quality products", Journal of Quality in Maintenance Engineering. Vol. 2 Issue 3, pp. 4-20. 1996. ISSN: 1355-2511

[42] P.A.C. Miguel. Estudo de caso na engenharia de produção: estruturação e recomendações para sua condução. "Produção". Vol. 17 Issue 1, pp. 216-229. 2007. ISSN 0103-6513
[43] J.W.M. Bertrand and J.C. Fransoo. "Operations management research methodologies using quantitative modeling". Journal of Operations \& Production Management, Vol. 22. Issue 2, pp. 241-261. 2002. ISSN: 0144-3577.

[44] E.M. Lakatos and M.A. Marconi. "Fundamentos de metodologia científica" .6. ed. São Paulo: Atlas. 2008. ISBN 85-224-3397-6

[45] D.C. Montgomery and G.C. Runger. "Applied statistics and probability for engineers", $5^{\text {nd }}$ Edition, Wiley \& Sons. 2010. ISBN: 978-1-118-53971-2

[46] N.R. Draper and H. Smith. "Applied regression analysis”. Wiley \& Sons. 1981. ISBN: 0471170828.

[47] G.A. Seber and A.J. Lee. "Linear regression analysis". Hoboken. 2003. ISBN: 978-0-471-41540-4.

[48] W. Weibull. "A statistical distribution function of wide applicability", Journal of Applied Mechanics - ASMC. Vol. 18 Issue 3, pp. 293 -297. 1951. ISSN: 2379-0431.

[49] J.F. Lawless. "Statistical models and methods for lifetime data". Wiley series in probability and mathematical statistics, Wiley \& Sons. 1982. ISBN-13: 978-0471372158.

[50] W.Q. Meeker and L.A. Escobar. "Statistical methods for reliability data". Wiley \& Sons 2003. ISBN-13: 978-0471143. 